\title{
Truck Drivers - The Under-Respected Link in the Supply Chain : A Quasi-Ethnographic Perspective Using Qualitative Appreciative Inquiry
}

\author{
Alvin J. Williams \\ Mitchell College of Business, University of South Alabama (USA) \\ E-mail: awilliams@southalabama.edu (Corresponding Author) \\ Babu P. George \\ Justice Hedge School of Management, NITTE (India) \\ E-mail: babu.george@nitte.edu.in
}

\begin{abstract}
Long-distance truckers are the lifeblood of complex supply chain networks. Thus, it is important to analyze ways to enhance the efficiency and effectiveness of these professionals. In particular, what factors contribute to their job satisfaction, quality of life, and overall success? These questions are partially answered in this study using the framework of appreciative inquiry to construct a comprehensive sketch of the day-to-day lives of long-distance truckers. While other aspects of the supply chain have been studied extensively, relatively less research has been directed toward understanding the nuances of the trucking way of life. The current paper offers some partial solutions, research directions, and managerial guidance.
\end{abstract}

Keywords: Truckers, supply chains, appreciative inquiry, and ethnography

\section{INTRODUCTION}

As organizations work to develop more sophisticated, responsive, agile, demand-oriented, process-driven supply chains, considerable attention is focused on enhancing the efficiency and effectiveness of every single component of global supply chains. An extraordinarily significant mainstay of modern-day supply chains is the truck driver. From an operational perspective, truckers are responsible for delivering the value expected by customers. Stank, et al. $(1999,2003)$ reinforce the point that organizations providing on-time and reliable delivery services and are responsive to customer needs are most likely to experience an increase in market share. Keller and Ozment (1999) suggest a direct relationship between the quality of delivery service offered by the motor carrier and the performance of truck drivers. Keller and Ozment further state "how drivers operate their trucks directly affects fuel efficiency, operating costs, and delivery performance, which in turn affects customers' perceptions of a given carrier's service quality and consequently influences that carrier's competitiveness."

From a marketing perspective, truckers are responsible for relationship building, customer satisfaction, and frontline problem-solving. In fact, Ellinger, et al. (2010) discuss in considerable depth the operational and strategic importance of empowering frontline service staff in third-party logistics (3PL) firms. Truckers play an integral role in facilitating the entire set of supply chain functions. Bode et al (2011) strengthen further the pivotal function of truck drivers in their study of truckers' impact on customer purchase behavior. The findings of Bode, et al. suggest a positive direct effect of personal contact quality, as provided by a delivery person, on sales. Abadi and Cordon (2012) discuss strategic resources and capabilities in supply chains and pinpoint the role of logistics and flow management as a key supply chain management process. As critical components of the logistical process, truckers are indeed a fundamental resource to be managed both strategically and operationally. Truckers are also value-added elements of any supply chain integration initiative. In their review of factors nurturing internal supply chain integration, Basnet and Wisner (2012) pay particular attention to distribution. As such, distribution effectiveness, facilitated by truckers, contributes directly to supply chain integration efforts. Thus, given the plethora of examples of the immense importance of truckers, it is imperative for supply chain researchers to allocate additional scholarly resources to enhancing understanding of how to elevate both the productivity and success ratios of truck drivers.

Truck drivers are an integral part of the supply chain, as evidenced by the nearly $70 \%$ of U.S. freight transported by this mode. Thus, it is essential for supply chain managers to better understand the operational and social variables that contribute to performance success in the truck driving profession. As truck driver job satisfaction and performance levels increase, there is a lessened probability of driver turnover. Cantor et al. (2011) identify driver turnover as a major source of supply chain disruption. They indicate three direct areas of impact of driver turnover on the supply chain. First, there are financial costs associated with training new drivers, drug screenings, and tractor repositioning costs. Secondly, turnover may negatively affect the capacity of the service component of the supply chain, including the possibility of having to refuse shipments due to a lack of drivers. Lastly, Cantor et al. suggest that driver turnover may impact supply chain disruptions through compromising safety with the hiring of 
inexperienced drivers. Collectively, these three concerns highlight the various costs linked to driver turnover and correspondingly to supply chain interruptions.

In the broader category of reducing the risk of supply chain disruptions, Wildgoose et al. (2012), place risk categories within the context of an organizational framework. One of the categories is management controls risk management, including labor availability. This speaks directly to the core of the current research in identifying and addressing some of the individual and social issues confronting drivers that might have a deleterious effect on job satisfaction and performance and the concomitant impact on labor availability. Thus, this paper contributes to the current body of thought by assisting in closing the knowledge gap regarding some of the social variables shaping the lives of truckers and thus impacting job performance.

Fundamental to truck driver productivity is the overall quality of life experienced by this important component of supply chains. To gain more insight on this population, it is germane to ask truckers to describe and discuss their work environment, degree of job satisfaction and the factors leading to either satisfaction or dissatisfaction, personal issues such as health and family concerns, the perceived importance of their jobs, and miscellaneous other themes related to the trucking way of life. Truck drivers' lives are also influenced by the nature and extent of the formal and informal controls imposed by their employers that impact both drivers' performance and operational performance and ultimately market performance (Saldanha, et al., 2013). As truck drivers work to balance the conflicting demands of their jobs with other aspects of their lives, they are quite prone to both role stress and emotional exhaustion (Kemp, et al., 2013). More specifically, Kemp et al. examine the conceptual and managerial linkages involving truckers' role conflict, role ambiguity, emotional exhaustion, internal communication, and organizational identification. The composite of quality of life variables, organizational concerns, and work environment leads to job dissatisfaction, which in turn leads to higher job turnover.

The current study provides a runway to flesh out some of the quality of work life concerns confronting professional truckers. Given the dependence of the domestic economy on millions of trucks and truckers to move goods, representing a key component of gross domestic product, more effort to address this population should be undertaken. The present research partially fills this knowledge gap by examining truckers' concerns from their own perspectives.

\section{BACKGROUND}

The trucking industry is enormously significant to the U.S. economy. According to the American Trucking Association's 'American Trucking Trends 2013, the following findings underscore the critical role of the trucking industry: (1) Trucks accounted for $68.5 \%$ of all domestic shipments (9.4 billion tons of freight) in 2012; (2) trucking generated $\$ 642.1$ billion in gross freight-related revenues in 2012; and (3) over 6.9 million people are employed in trucking-related industries. By any measure, trucking is a massive sector of the economy.
Truck drivers, by virtue of their position in the supply chain, are in fact drivers of the economy. Any actions, behaviors, policies, regulations, or work environments that negatively impact professional truckers, correspondingly affect negatively the economy. Thus, it is important to better understand the myriad factors contributing to truck driver performance and overall job satisfaction.

The job and life of long distance truckers is fraught with both folklore of adventure and the challenges of basically working alone and the frequent absences from home and family. In a comprehensive study of longdistance truckers discussing their jobs, Johnson, et al. (2010), uncovered the following factors identified by trucker respondents that would improve quality of life: fewer government rules and regulations, more time at home, more parking availability for their trucks, greater respect for the trucking profession, spending less time waiting to load and unload their vehicles, better quality truck stops, driving newer trucks, and fairer treatment by police. All of these work environment factors were found to impact perceptions of work quality of life. Collectively, these variables influence driver job satisfaction, driver retention, and turnover rates.

More specifically, Williams, et al. (2011) identify a comprehensive list of truck driver retention variables: pay, personal safety, time at home, equipment, career advancement, workload, dispatcher, career development, company reputation, relationships with customers, relationships with other drivers, company recognition and rewards, cargo, loading and unloading requirements, realistic recruitment tactics, top management, and company orientation programs. Given the importance of truckers and the total costs associated with trucker replacement, retention and lower rates of turnover are key to long-term carrier profitability.

\section{METHODOLOGY}

Given the objectives of the study, it was important to identify an appropriate mechanism to deliver rich and useful results. Upon careful evaluation of various options, the researchers selected appreciative inquiry (AI) as the most appropriate approach. Appreciative inquiry, also known as 'the discipline of positive change', has evolved into an admired paradigm underpinning a variety of qualitative research. Appreciative inquiry is a powerful transformative force capable of changing the lives of the inquired.

Cooperrider, et al. (2008) define AI as "the cooperative search for the best in people, their organizations, and the world around them" and "involves the discovery of what gives life to a living system". It evolved as an antidote to the challenges posed by problem-oriented inquiry, frequently focused on identifying shortcomings in systems. Pragmatically, AI involves collecting information from populations of interest regarding positive aspects of their situation or what they consider good about their situation and then using that information to assist in countering the more negative aspects of their environment. Appreciative Inquiry is built upon the power of positive thinking. The AI researcher constructs a plan of action for improving their clients' situation and guides the clients to execute the plan. 
Many traditions have evolved within the AI paradigm. As noted above, AI emerged as a revolt against dominant inquiry systems that overly focus on the 'negative'. Many AI researchers discourage interviewees from talking about problems they face and ask them to singularly search for glimmers of hope. However, this practice of AI often results in the opposite bias - excessive focus on the 'positive.' Hence, we adopt a more balanced approach which tries to identify both the positive and the negative and then search for ways to employ the positive to help transform the negative.

AI informs a four-stage methodology, which embraces discovering, dreaming, designing, and doing. In the discovery phase, the researcher attempts to unearth what is good in the seemingly bad situation; in the dreaming phase, study participants are encouraged to dream ideal scenario(s); in the design phase, a blueprint of action is prepared that guides participants towards the goal(s) dreamed in the previous stage; and, the final stage is the stage of action wherein participants actually execute the blueprint in their real lives. In the present research communication, given the timeframe involved and the complexity of execution, only the first three stages are included, to the exclusion of the 'doing' component.

The current study also builds on the qualitative research tradition of ethnography. Ethnographic research allows for detailed participant-observer encounters in actual settings as events and behaviors transpire, with a focus on how people live their lives (Anderson, 2009; Boddy, 2011). The quasi-ethnographic approach used in the current study is a microcosmic reflection of the data-richness embodied in full-scale ethnographic studies in business.

\section{THE STUDY}

The study was conducted in five truck stops and waiting areas located in and around Anchorage, Alaska, USA. The locations were chosen because of traffic patterns, volume of traffic, and convenience. To achieve the study objectives, long hours were spent with truck drivers, observing their conversations and behavior, taking notes from their diaries, and contacting some of their relatives for additional information and input. The researcher also hitchhiked occasionally to gain a close-up perspective on the particulars of their everyday work lives as they drive. The in-depth nature of the data collection experience allowed for richer and more robust data quality.

The 30 respondents were all male, with a mixture of whites, African-Americans, Latinos, and Asian truck drivers. Responses were collected over a three-month period. Over this time period truckers were approached randomly at the five truck stops. Initially, a general discussion was initiated about general themes (e.g., weather, traffic congestion, etc.). Following the 'opening,' 'warmup' type comments and generic conversation points, the researcher introduced himself as an academic conducting a study on the lives of interstate, long-distance truck drivers. Specific care was taken to ensure they understood that the study focus was on the lives of truckers, in their own words and perspectives. The questions were communicated in the language of truckers by providing examples and explanations.

The research questions and the ensuing conversations addressed five basic themes: (1) How do you feel about being a truck driver? (2) What factors influenced you to select truck driving as a career? (3) What are the various pros and cons of this career field? (4) Thoughts on various trucking industry business models - self-employed drivers contracting with carriers, small independent truck drivers, etc.; and (5) Do you think the world is fair to truck drivers? If not, how do you creatively overcome some of the unfairness?

Considerable effort was expended to use probing questions to gain as much depth as possible. Following the spirit of appreciative inquiry and ethnographic research, the researcher engaged respondents and attempted to uncover their true feelings, with more emphasis on the positive, about their lives as professional truckers.

The remaining sections of the paper build on the framework set by the themes in the five questions. Direct quotes from truckers constitute the bulk of the following paper sections, along with the integration of conceptual material from the trucking and transportation literature.

\subsection{On Antecedents}

One of the research questions probed the motivation to become truck drivers. Many of the drivers responded that this was one of the few professions that offered decent pay for the not-so-highly educated. Thanks to the shortage of truck drivers and their overall economic importance, this profession offers a secure career path for many. Respondents expressed confidence in the mobility or portability of their truck driving experiences, regardless of their location in the U.S. That said, one of the respondents noted: "It is not easy to become a truck driver. The easiest way is to approach a fleet company that would train you inhouse for a commercial driver's license and give you a job. Well, most of them have apprentice programs if you give some sort of long term commitment. He added, "Quite contrary to belief, fleet companies like to train newbies rather than recruiting old hands who are inflexible to changes - especially technological changes".

Research conducted by Wenger (2008) indicates that truck drivers considered money, an interest in trucks, driving, the truck-driving community, and freedom as their primary incentives for becoming truck drivers. Our textual analysis indicates that at least three of the young drivers whom we interviewed used terms like exploration, sightseeing, exotic, adventure, variety, experience, different food, new places, different culture, etc., in connection with why they enjoy truck driving. This viewpoint leads to possible linkages between truck driving and touristic motivations. Truck driving does offer some unrivalled chances to see different places and experience different cultures. Yet, older drivers to whom we asked this question mostly restricted their responses to the monetary value of truck driving. Finally, as Wenger (2008) notes, freedom for truck drivers is not free: high fuel costs, sleep deprivation, physical and emotional health issues, lack of safety, questionable company practices, strict government 
regulations, and related concerns provide a set of disincentives regarding trucking as a career option.

\subsection{On Mental and Physical Health}

Research shows that a large number of seasoned truck drivers suffer sedentary habits, inadequate diet, obesity, and hypertension (Saltzman and Belzer, 2007). According to Korelitz, et. al., (1993), a large percentage of male truck drivers smoked cigarettes $(54 \%$ vs. $30 \%$ of U.S. white males), did not exercise regularly (92\%), were overweight (50\% vs. $25 \%$ of U.S. white males), were not aware they had high blood pressure ( $66 \%$ vs. $46 \%$ of U.S. population); also, $23 \%$ of surveyed truck drivers tested positive on one measure of alcoholism. Collectively, these statistics do not bode well for the long-term health status of American truckers.

One recent study reveals that U.S. truck drivers weigh more than the general population, with a difference in mean body weight of $13.5 \mathrm{~kg}$ for males and $15.4 \mathrm{~kg}$ for females (Guan, et al., 2012). "A lot of us are obese: not because we eat a lot, but because we sleep a lot less", describes the situation by one of our respondents. Some of our driver respondents asked us to observe their legs; evidently, most of them suffered from some level of thrombosis. Guam, et al. (2012) makes a more remarkable observation - the physique of truck drivers now is significantly different from that of their counterparts a quarter century ago. This might imply changes in food habits and working conditions over the last 25 years or so.

Monotony and the stress lead some drivers to drugs (Guinn, 1983). Drug testing has become too frequent, thanks to this: "We get drug-tested at the commercial driver's license stage; then occasionally by the fleet management and at times by police, especially when we have accidents. The federal Department of Transportation does it again during commercial driver's license recertification", explains one of the drivers.

Sexual health of drivers used to be a major concern. However, as a result of strict enforcement coupled with peer education and health care promotion, this is not much of an issue now. "For me, the women I encountered once in a while at the rest areas were like my fuel; now that has become a thing of the past (just like drug use)", recounted a senior driver. That said, we got clues from some young drivers that they were using adult dating sites on their smart phones to secure services.

\subsection{On Safety and Security}

At no moment while on duty are truck drivers spared from safety and security concerns (McDonald, 1984). Given the safety issues, fleet management companies are increasingly committing resources to remotely monitor and manage their trucks. "Some fleet owners can remotely control the speed of the truck; my previous owner did that once when I exceeded my daily hours and continued to drive. After some warnings, they would force me to stop", explains one driver. Most small fleet owners cannot afford to invest a lot on these technologies and they trust drivers for the security of consignments in the cargo area: "Containers are locked and sealed; not only that I can't steal but also that I have to ensure that no one else break in", he quips. After that, he reveals his real fear about safety: "At times, I am really worried knowing that I am carrying flammable substances". Big fleet owners use patented technologies to remotely lock and unlock the cargo space. A lot of academic studies relate driver compensation and scheduling practices with driver safety (Mackie and Miller, 1978; Rodriguez, Rocha, Khattak, and Belzer, 2003; Rodriguez, Targa, and Belzer, 2005). But, as our interviews reveal, there is more to it.

While salaries in many cases are good, truck driving is not for everyone: "At times, I had to drive more than 13-14 hours with only coffee breaks in between; of course, I need to call and inform police and get their escort whenever I cross the 11-hour legal limit. If I don't do that, and if met with an accident, I would get 10 years in jail. But, say, when you drive through the inhospitable terrains of desert southwest you won't find a place to safely park and rest", one respondent shared.

Another respondent laments: "Sometimes we have to show up at 6 a.m. in the warehouse and are not allowed to leave before noon; it's like punishment in hell." This is a big problem with big clients. Many small freight companies don't want to do business with such clients since the drivers don't want to go through this punishment. The researcher was told that the bigger a client, the lower the quotes for freight services, and the higher will be the punishment to the freight companies if the deadlines are not perfectly met". However, this respondent is not overly pessimistic: "Some companies do give us ample time; but others severely punish us for being late...like not paying wages, by making us wait until the end of the current shift, often up to 12 hours; even when we have valid excuses like medical certificates or report of a traffic jam." His assistant, a young graduate of 27, sitting beside him, sipping a cup of coffee, adds: "well, it's understandable- like when the product is perishable and when the unloading facility is booked for all other slots". This assistant driver says he has a master's degree in history and that he could not find another way to repay his student loan and hence he is into this.

One driver whom we interviewed seemed a little too forthcoming in revealing what he termed a trade secret: "During peak seasons such as Christmas and Thanksgiving, fleet owners encourage us drivers to keep multiple log books in the truck; so, if police catch us, the odds are high that at least one of them will show that we are within safe driving hours. Another way to circumvent regulations is to take the risk and drive via toll free, weighing station free, interior roads". If things happen this way, it is highly detrimental to public safety and also is a clear violation of rules. Despite these, most drivers seemed to be conscious of the consequences of rule violations. "If I am caught up in heavy traffic, unlike private cars, I can't escape by taking a random exit: police might question and fine me", notes a respondent. Management commitment to safety influence individuals' perceptions of safety culture (Arboleda, et al., 2003) and one reason these truck drivers take risks could be because of their perception that management expect and reward such behavior.

Some of them did not mind bending the rules a little bit, and they were candid about it. According to one driver, 
"It is illegal to carry hitch-hikers (especially if I crash somewhere); insurance company can deny my claims of coverage. But, I let someone on board once in a while if I feel that he would be good company or if I feel that he is really in need of my help". This driver did not forget to add a few words of appreciation for private car drivers: "Most car drivers are nice to us; they give way for us to merge to the interstate. Some give a flash with their headlights and I give them back a flash with my trailer light once I merge ahead of them." Without the cooperation of the drivers of smaller vehicles, it is virtually impossible to drive huge trucks he adds. His pal standing by him adds: "Actually, people with tunnel vision merging with highway are my biggest nightmare as a truck driver".

The United States is very diverse geographically, which makes cross-country trucking very hard. Most truck drivers interviewed were trained to drive in snowy-icy conditions and they all attest to the many challenges. Driving between Alaska and the lower 48 States in the U.S. is a perilous act, even in the summer. One driver explains: "Steeply inclined roads are the most difficult places for me; the truck needs a lot of braking... at times, the brake pads get overheated and breaking effect decreases substantially. One of my friends recently had to use a 'run away truck ramp', as the last resort".

It should be noted that the Federal Motor Carrier Safety Administration had released new service regulations for truck drivers in the United States and these regulations are going to take effect in July 2013. These new regulations propose a more scientific approach to acceptable driver behavior.

\subsection{On 'Relationships On-The-Go'}

Strikingly, our interviews reveal truck driving runs in some families - crossing generations. A few of the drivers indicated three generations of truckers in their families. One clarified: "You may find that, for most truck drivers, there is a near or distant relative already into truck driving". This feeder route is an important source of trucking talent, even with the proliferation of professional driving schools. It is not uncommon to find partners: father-son, husband-wife, or just couples. Such partnerships, among other benefits, would make life easier for them on long drives. This gives the partial feel of being home even though they are away from home. One such 'family driver' states: "we can demand a premium since we can drive 22 hours non-stop in two shifts and can reach the destination faster". He adds: "I have seen some of the enduring partnerships here; each one's life is in the hands of the other and you don't want to have messed up relationships and drive together 11 hours".

Respondents seem to support the notion that malefemale partnerships are more likely among long distance truck drivers. Many of those who start as professional coworkers and as friends finally become bonded couples. Such families are significantly more likely to produce future drivers, too. According to some drivers, increasing popularity for such 'couple-partnerships' mean lowered rates of casual sexual encounters with strangers on the go. This results in lowering reported cases of sexually transmitted diseases among truck drivers.

\subsection{Boredom versus Passion}

Driving non-stop for a thousand miles a day is heavily taxing upon the body (Crum and Morrow, 2002). Frequent irregularities in the schedules add to the physiological stress, performance degradation, and fatigue (Mackie and Miller, 1978). One driver with whom the first author of this paper took a short trip confessed: "I roll down windows and listen to loud music if I get tired while driving; I keep eating cereals; frankly, I take a nap if it is a straight road". There is a positive side to this, a nourishing experience for the mind: "We truck drivers can't stop becoming philosophers: it's amazing the variety of people whom we see on the road - by the way, this just matches the variety of landscapes we push through while driving from Anchorage to Seattle", observes one of the few 'philosopher-drivers' interviewed.

Snacking is one of the most popular ways to get over boredom. "I eat a lot of sunflower seeds and snacks and take a lot of energy drinks; caffeine is good in the short term but it will make you feel disinterested in everything after a while", in the words of one driver respondent. Young drivers do a lot of social networking on the go. According to some respondents, this is major cause of road accidents. But some disagree with this - they argue that being able to interact with others while driving keeps them awake and alert. Previous studies suggest that drivers would like to be in live communication loops and that feedback by technology is acceptable, if designed and implemented properly (Roetting, et al., 2003). Truck drivers generally maintain a high degree of camaraderie. They treat each other as close pals, brothers, and sisters. More experienced drivers nurture the professional growth of the young. Like in a close-knit gathering, many drivers use Citizens' Band radio to chit-chat. Tech savvy young incumbents among them tweet about traffic interruptions and "police traps" for the benefit of other drivers nearby.

Despite the inherent boredom induced by the monotony of the job and the strain upon body and mind, many drivers are born evangelists for a career in truck driving: "Believe it or not, many truck drivers are drive addicts; they love what they do and forget how long they have been driving", says one driver respondent. He goes on: "I learned responsibility and independence from my job; these are the greatest things I could teach my kids". His coworker exhibited a passion that exuded a 'work is worship' kind of spirit: "I know my client handles products just in time ...I am part of a chain and if I fail, all the related operations will also fail; I can't let them suffer for anything within my control. Yet, at times, cost savings measures backfire." Risk is often metamorphosed into a spirit of adventure, too: "I am an ice road trucker...I drive from Anchorage to Seattle and back, even in the heaviest winter; I have seen death face to face, so many times. Now, I have a playful attitude towards life", adds a driver. Independence came as a recurring theme in the discussion, too. One driver expressed this feeling very well: "As I driver, the most rewarding thing for me is my independence; I am my boss between the pickup and the drop off point, if I play the game correctly". 


\subsection{On Technology}

Truck drivers recognize that technology is a doubleedged sword: "GPS tracking in real time has made us robots: good servants but bad masters. On the good side, we can't drive past the stipulated maximum hours and we get proper rest; on the bad side, we live under constant monitoring and control", reflects one 25 year old community college graduate who recently accepted a driver's assistant position. He sees the benefits outweighing the costs: "However, thanks to GPS technology, CB (citizens band) radio, and real time traffic alerts, our operations have become much more efficient; we drive less, but earn more". He adds: "Now, instead of stopping and watching a movie, I watch it on my tablet; I play games on my tablet to get rid of boredom (while I drive)". According to traffic police sources, tech-addiction among truck drivers is increasingly becoming a cause for alarm. Despite the advantages in technology, these drivers do not want their driving behavior monitored. "Personally, I don't like to be monitored by someone from a remote point even if it is for my safety; I don't mind my GPS unit giving me a warning when I speed, though", according to one respondent. Older drivers often find it difficult to grapple with the technology. The fear of technology is also about the fear of the future. One driver went so far as to wonder what the future of truck driving would be, assuming something like the much publicized Google self-driven cars replacing human drivers.

During the discussion on technology, a lot of time was spent on information and communication technologies. However, occasionally, other topics were mentioned. One driver quipped jokingly: "Most people still don't know that trucks invariably use manual stick shifts and that it is not a cakewalk". Some talked about the sustainability issues associated with innovations in truck design. "My company is slowly introducing natural gas and hydrogen trucks; also, auxiliary power units to keep us warm/cold during nights when the engine is stopped. More mileage, low noise, smoother driving", noted one 'proud' driver respondent. It was endearing for the interviewers to learn that average truck drivers do care about these issues.

\subsection{On Management Models}

While many transaction cost and agency theorists predicted the dominance of self-employed drivers who contract with carriers, this model accounted for less than a third of the U.S. trucking activity (Nickerson and Silverman, 2004). Many of the truck drivers whom we interviewed were small independent truck owners who only had one truck. They have contracts with big fleet owning flagship companies and even big retailers like Wal-Mart: "Wal-Mart does have a freight arm but most of us are not treated strictly like employees. We own our trucks and are paid a lump sum from which we pay for gas. So, we try to reduce fuel consumption. Of course, I get a rebate for gas; often, I pay only half the market price to fill my tank. However, if the price of gas goes below a particular level, I have to give back some money to Wal-Mart", one driver explained the intricacies of the deal. According to this owner-driver, the fleet companies charge their clients the subsidy they pass on to him for the cost of gas, in addition to the shipping fee. We also interviewed a couple of drivers who claimed to be truck drivers officially employed by Wal-Mart, driving Wal-Mart owned trucks. "I am a Wal-Mart staff driver, one in around 7000; Wal-Mart pays for everything, including gas. That's the good part of it. The bad part is, I don't have the choice to say no to a freight request, unlike independent truck owneroperators. However, we normally transfer general merchandise items. Wal-Mart employs freight companies and independent owner operators for grocery transfers". Yet, we must admit that our interviews did not help us to get full clarity of the different kinds of deals practiced: "Even though I am an independent owner, I own only the truck; the trailer is owned by Wal-Mart", clarifies one driver.

Most contracts with independent truck owners are for the short term. However, there are exceptions to this, as one driver narrates: "I have a five-year contract with my shipping company. I demanded a long- term commitment since they wanted to thoroughly modify the interior of my truck to suit their requirements: specific control buttons to the trailer, for instance. I know I cannot use my truck the same way for any other business. Long term contracts help me to ensure that I get money to pay for my loan". While the bargaining power of small-scale truck drivers is quite weak in such scenarios, they often organize under the umbrella of trade unions. "Strictly, I don't want to be part of any union; yet I do: that's the only way I can hope to get a decent wage", reflects one of them. Unions also help them to protect their jobs and ensure decent wages. Many whom we interviewed indicated that fleet owners employ inexperienced drivers and commercial driver's license students to save on wages. Some fleet companies constrain the wages and other benefits with the intention of letting the senior drivers leave. The DAC (Drive-A-Check) reports (this report, mostly sourced from former trucking employers, summarizes the driving history of a commercial driver) are another weapon in the hands of abusive employers to control the drivers. Among other things, this practice has potential road safety implications.

One of the drivers air a view widely held by the supply chain managers of retailing and fleet managing firms: "I know I am a reliable guy; but if I were a company that depends upon time-sensitive shipping, that too often, I wouldn't contract with independent owners: it's just that the trucker has far less reputation to lose for a delayed shipment". Yes, the reason why sensitive shipments do not go to independent owner-operated truck drivers is this trust deficit. Then, there is the efficiency issue: "Most independent contractors like me transport LTL (less than truck load) needs. When a company needs to ship full truckloads multiple times, it might think of buying trucks and hiring drivers". In the course of our interviews, we also came to know of some of the healthy practices being adopted in the fleet industry: "The previous company I worked with offered to pay for all my truck maintenance requirements. The contract was such that they would pay for all maintenance if I warned of potential problems in advance or they would fine me heavily if my truck breaks down (in addition to the cost of repairs)". We must add that such practices are not yet in the mainstream. 


\subsection{On Compensation}

Belzer, et al. (2002) studied compensation and safety. As expected, the overall conclusion was that of a positive relationship until compensation reached a level, after which the relationship didn't get any stronger. Generally, unless you are a regular staff driver, compensation is tied to the miles driven. One of the pleasant surprises we had was when we heard of the pay structure, as described by a driver: "I know some truck drivers making close to $\$ 300 \mathrm{~K}$ a year; I come back home every other day, compromising my pay. I earn around $100 \mathrm{~K}$ gross and $60 \mathrm{~K}$ net, after fuel and maintenance expenses. Believe it or not, it is the highest paying non-college educated job". The response by another driver was more balanced: "I earn double the income of my son's school teacher, but I get only half as much respect in society." This response on 'lack of respectability' associated with the trucking profession is consistent with the findings of Johnson, et al. (2010, 2011).

While some compensation scenarios are more positive, others lean toward the opposite end. One driver recalled the days when she had to sit at home without a job. She said she spent around $\$ 5,000$ for a commercial driver's license, got an opportunity as a junior driver for just four months and then the trucking company laid her off without even citing a valid reason. And she bets her experience is not uncommon or atypical. Unionization efforts in the U.S. are expected to see much greater success with the passing of the proposed Employee Free Choice Act.

This driver also observed that the new drivers often have to go through a period of stress and low pay before they could stabilize. While it is easy to make $\$ 100 \mathrm{~K}$ or above if you are a veteran driver with your own truck, new drivers start from around $\$ 35 \mathrm{~K}$ a year, according to another respondent. A major problem in finding truck drivers is related to the strict DUI (driving under the influence of alcohol or drugs) standards that recruiters follow. It is often hard to find applicants free of drug and DUI incident history. The driver turnover rate in the industry is often up to $300 \%$, observes Lemay and Taylor (1988). Min and Lambert (2002) cited 100 to 200 percent annual driver turnover rates in the for-hire trucking business.

\section{FUTURE RESEARCH DIRECTIONS}

As the role of truckers escalate in importance in global supply chains, research agendas can be formulated around many factors, including the individual and social variables that impact driver turnover, job satisfaction, overall job performance, customer satisfaction levels across the supply network, and the extent of firm profitability, growth, and return on investment. Given the foundation in the current study to examine the day-to-day lives of long-distance truckers, future research should focus some efforts on crosscultural studies. How do the lives of truckers differ across cultural boundaries and what factors influence those differences? DeCroon et al. (2002) study job stress, fatigue, and job satisfaction in Dutch lorry drivers. This is one example of how the current study can build on studies in other countries that address similar concerns linked to the working lives of truck drivers. Concomitantly, Baulk and Fletcher (2012) examine sleep patterns, at home and away, of Australian truck drivers. This is an additional example of how individual factors such as sleep impact job performance. Again, building on the current study, additional individual factors affecting the quality of driver life could be studied across cultures.

All truck drivers are not created equal. Are there differences in need segments that can be addressed to mitigate some of the negative aspects of the job that impact driver turnover, job satisfaction, and overall performance? Williams, et al. (2011) suggest the use of truck driver needbased segmentation in developing driver retention programs. Each category of driver needs offers opportunities to tailormake retention initiatives. The current study could catapult segmentation-based research categorizing the types of individual need structures of truck drivers, thus further advancing efforts to identify variables management might use to enhance job performance and ultimately the performance of the supply chain.

Finally, the quasi-ethnographic approach used in the current paper could be extended to a full-blown ethnographic research effort, focusing on interviews of greater depth and scope. In future research, interviewers could spend more time with truck drivers, across situations, contexts, and environments to discern more, at the root level, about their concerns, apprehensions, aspirations, experiences, and expectations of a career in long-haul truck driving. To add to the richness of future research in this realm, longitudinal ethnographic research designs offer considerable promise.

\section{IMPLICATIONS, SUMMARY AND CONCLUSIONS}

The obvious question is 'where do we go from here?' Professional truck drivers are an enormously significant component of the U.S. economy and the overall quality of life that we experience as both businesses and consumers. Yet, for all of their contributions and importance, there are major gaps in the capacity of professional truck drivers to enjoy some semblance of a quality of life that other professions take for granted. While many circumstances are peculiar to this work population, it is incumbent upon carriers, truckers, and the entire supply chain community to work collaboratively to ensure upgrades in job satisfaction and the overall life quality stature of professional truckers.

Much is at stake when supply chain partners fail to respond integratively to the challenges posed by trucker job dissatisfaction, work environment issues, and family/personal matters that are often exacerbated by the nature of the job. More particularly, these factors lead to higher driver turnover, which lead further down a perilous path of even more job dissatisfaction and more turnover. This results in high replacement costs. The cost of replacing a single driver may range from $\$ 2,200$ to $\$ 21,000$ (Suzuki, et al., 2009). Suzuki, et. al. further state that if replacement costs are in the $\$ 8,000$ category per trucker, with the average medium-sized carrier employing 1,000 drivers, at $100 \%$ turnover, an annual expense of $\$ 8$ million is a real possibility. This rate of turnover is hardly sustainable over 
the long run. Thus, extensive effort is required to explore options for remedying this situation. The current study makes a step in the direction of uncovering the genuine, heartfelt concerns of truckers through the use of appreciative inquiry and a quasi-ethnographic approach. The work environment, and attendant challenges, is illustrated and expressed in the authentic, no-holds-barred tone of truckers telling 'their story' in 'they own way.' One of the current researchers immersed himself in the environment and milieu of truckers to really acquire a more valid perspective on the essence of what it means to be a professional trucker. Compilation and analysis of truckers' actual comments comprise the thrust of the current research.

The present study corroborate the findings of Johnson, et al., (2011) regarding some of the positives associated with a trucking career - allows for adventure and new experiences, more or less financially attractive, instills a sense of work independence and some degree of control, and offers steady employment. Given these favorable job attributes, carriers and others must build on these qualities to recruit, retain, and develop ensuing generations of professional truckers. Again, congruent with Johnson, et al. (2011), gargantuan strides must be made to ensure more time at home for long-distance truckers. Definitive, substantive, and creative efforts must be expended by all supply chain partners to configure schedules to include more home time. Johnson, et al.'s other suggestions include: (1) balancing the pay and benefit packages to counterbalance some of the job negatives; reducing driver stress by making delivery schedules more realistic and working with dispatchers and others to show more respect to drivers; and reducing and/or assisting with the amount of required paperwork, governmental or otherwise. Jointly, these suggestions or recommendations have the capacity to vastly enhance the quality of work life of long-distance professional truckers.

\section{REFERENCES}

Abadi, J.F. and Cordon, C. (2012). Developing a Framework for the Identification and Analysis of the Strategic Resources and Capabilities in Supply Chains. Operations and Supply Chain Management, 5 (2), pp. 59-75.

American Trucking Association, 'American Trucking Trends 2013,' http://www.truckline.com/article.aspx?uid=d62a253db830-4fa3-b069-f7f8ff5d40df

Anderson, K. (2009). Ethnographic Research: A Key to Strategy. Harvard Business Review, 87 (3), 24.

Arboleda, A., Morrow, P. C., Crum, M. R., \& Shelley II, M. C. (2003). Management practices as antecedents of safety culture within the trucking industry: similarities and differences by hierarchical level. Journal of Safety Research, 34(2), pp. 189-197. doi:10.1016/S0022-4375(02)00071-3.

Basnet, C. and Wisner, J. (2012). Nurturing Internal Supply Chain Integration. Operations and Supply Chain Management 5 (1), pp. 27-41

Baulk, S.D. and Fletcher, A. (2012). At Home and Away: Measuring the Sleep of Australian Truck Drivers. Accident Analysis \& Prevention, 45 (supplement), pp. 36-40.

Belzer, M., Rodriguez, D., \& Sedo, S. (2002). Paying for Safety: An economic analysis of the effect of compensation in truck driver safety. ID: http://ai. volpe. dot.
gov/CarrierResearchResults/CarrierResear (Washington,

DC). Retrieved from http://www.getcited.org/pub/103423303

Boddy, C.R. (2011). 'Hanging Around with People': Ethnography in Marketing Research and Intelligence Gathering. The Marketing Review, 11( 2), pp. 151-163.

Bode, C., Lindemann, E., and Wagner, S.M. (2011). Driving Trucks and Driving Sales? The Impact of Delivery Personnel on Customer Purchase Behavior. Journal of Business Logistics, 32 (1), pp. 99-114.

Cantor, D.E., Macdonald, J.R., and Crum, M.R. (2011). The Influence of Workplace Justice Perceptions on Commercial Driver Turnover Intentions. Journal of Business Logistics, 32 (3), pp. 274-286.

Cooperrider, D. L., Whitney, D., Stavros, J. M. (2008). Appreciative Inquiry Handbook (2nd ed.). Brunswick, $\mathrm{OH}$ : Crown Custom Publishing, Inc.

Crum, M.R. and Morrow, P.C. 2002. The influence of carrier scheduling practices on truck driver fatigue. Transportation Journal, 42(1), pp. 20-41.

de Croon, E.M., Blonk, R.W.B., de Zwart, B.C.H., Frings-Dresen, M.H.W., and Broersen, J.P.J. (2002). Job Stress, Fatigue, and Job Dissatisfaction in Dutch Lorry Drivers: Towards an Occupation Specific Model of Job Demands and Control. Occupational and Environmental Medicine, 59, pp. 356-361.

Ellinger, A.E., Keller, S.B., and Elmadg-Bas, B.A. (2010). The Empowerment of Frontline Service Staff in 3PL Companies. Journal of Business Logistics, 31(1), pp. 79-98.

Guan, J., Hsiao, H., Bradtmiller, B., Kau, T.-Y., Reed, M. R., Jahns, S. K., Loczi, J. (2012). U.S. Truck Driver Anthropometric Study and Multivariate Anthropometric Models for Cab Designs. Human Factors: The Journal of the Human Factors and Ergonomics Society. doi: $10.1177 / 0018720812442685$

Guinn, B. (1983). Job satisfaction, counterproductive behavior and circumstantial drug use among long-distance truckers. Journal of Psychoactive Drugs, 15(3), pp. 185-188. doi:10.1080/02791072.1983.10471947

Johnson, J.C., Bristow, D.N., McClure, D.J., Schneider, K.C. (2010). Long-Distance Truck Drivers Discuss Their Occupations. Journal of Transportation Law, Logistics \& Policy, 77(1), pp. 55-75.

Johnson, J.C., Bristow, D.N., McClure, D.J., Schneider, K.C. (2011). Determinants of Job Satisfaction among LongDistance Truck Drivers: An Interview Study in the United States. International Journal of Management, 28 (1/2), pp. 203-216.

Keller, S.B. and Ozment, J. (1999). Managing Driver Retention: Effects of the Dispatcher. Journal of Business Logistics, 20 (2), pp. 97-120.

Kemp, E., Kopp, S.W., and Kemp, E.C. (2013). Take This Job and Shove It: Examining the Influence of Role Stressors and Emotional Exhaustion on Organizational Commitment and Identification in Professional Truck Drivers. Journal of Business Logistics, 34 (1), pp. 33-45.

Korelitz, J. J., Fernandez, A. A., Uyeda, V. J., Spivey, G. H., Browdy, B. L., \& Schmidt, R. T. (1993). Health habits and risk factors among truck drivers visiting a health booth during a trucker trade show. American Journal of Health Promotion, 8(2), pp. 117-123. doi:10.4278/0890-11718.2.117

LeMay, S.A. and Taylor, G.S. (1988). Truck driver recruitment: Some workable strategies. Transportation Journal, 28(1), pp. $15-22$

Mackie, R. R., and Miller, J. C. (1978). Effects of hours of service regularity of schedules, and cargo loading on truck and bus driver fatigue. $\quad$ Retrieved from http://trid.trb.org/view.aspx $? \mathrm{id}=82782$ 
McDonald, N. (1984). Fatigue, Safety and the Truck Driver. Retrieved from Last accessed from http://trid.trb.org/view.aspx?id=200829 on 10 October 2012.

Min, H. and Lambert, T. (2002). Truck Driver Shortage Revisited. Transportation Journal, 42 (2), pp. 5-16.

Nickerson, J. A. and Silverman, B. S. (2003). Why aren't all Truck Drivers Owner-Operators? Asset Ownership and the Employment Relation in Interstate for-hire Trucking. Journal of Economics \& Management Strategy, 12(1), pp. 91-118. doi:10.1111/j.1430-9134.2003.00091.x

Rodriguez, D. A., Rocha, M., Khattak, A. J., \& Belzer, M. H. (2003). Effects of truck driver wages and working conditions on highway safety: Case study. Transportation Research Record: Journal of the Transportation Research Board, 1833(-1), pp. 95-102.

Rodriguez, D. A., Targa, F., and Belzer, M. H. (2005). Pay incentives and truck driver safety: a case study. Industrial \& Labor Relations Review, 59, 205.

Roetting, M., Huang, Y.-H., McDevitt, J. R., \& Melton, D. (2003). When technology tells you how you drive-truck drivers' attitudes towards feedback by technology. Transportation Research Part F: Traffic Psychology and Behaviour, 6(4), pp. 275-287. doi:10.1016/j.trf.2003.09.001

Saldanha, J.P., Hunt, C.S., and Mello, J.E. (2013). Driver Management that Drives Carrier Performance. Journal of Business Logistics, 34 (1), pp. 15-32.
Saltzman, G. M., \& Belzer, M. H. (2007). Truck Driver Occupational Safety and Health: 2003 Conference Report and Selective Literature Review. Retrieved from http://trid.trb.org/view.aspx?id=814997

Stank, T.P., Goldsby, T.J., and Vickery, S.K. (1999). Effect of Service Supplier Performance on Satisfaction and Loyalty of Store Managers in the Fast Food Industry. Journal of Operations Management, 17 (4), pp. 429-47.

Stank, T.P., Goldsby, T.J., Vickery, S.K., and Savitskie, K. (2003). Logistics Service Performance: Estimating Its Influence on Market Share. Journal of Business Logistics, 24 (1), pp. 27 55.

Suzuki, Y., Crum, M.R., and Pautsch, G.R. (2009). Predicting Truck Driver Turnover. Transportation Research Part E, 538-550.

Wenger, J. (2008). Freedom Isn't Free: Voices from the Truck Driving Industry. NEW SOLUTIONS: A Journal of Environmental and Occupational Health Policy, 18(4), pp. 481-491. doi:10.2190/NS.18.4.e

Wildgoose, N., Brennan, P., and Thompson, S. (2012). Understanding Your Supply Chain to Reduce the Risk of Supply Chain Disruption. Journal of Business Continuity \& Emergency Planning, 6 (1), pp. 55-67.

Williams, Z., Garver, M.S., and Taylor, T.S. (2011). Understanding Truck Driver Need-Based Segments: Creating a Strategy for Retention. Journal of Business Logistics, 32(2), pp. 194-208.

Alvin J. Williams is Distinguished Professor of Marketing, Mitchell College of Business, University of South Alabama (USA). He is past Editor, Journal of Supply Chain Management and serves on the editorial boards of several supply chain and business journals. His research has appeared in Industrial Marketing Management, Journal of Supply Chain Management, Supply Chain Management Review, and the Journal of Personal Selling and Sales Management. His current research interests focus on supply chain integration and buyer-seller relationships. He has a Ph.D. from the University of Arkansas (USA).

Babu P. George is currently the Coordinator of Research in the Business School of NITTE University, India. He is a visiting professor in the business administration area at Alaska Pacific University, USA, and SMC University, Switzerland. $\mathrm{He}$ is the editor of International Journal of Qualitative Research in Services, published by Inderscience. He serves on the governing-advisory boards of multiple nonprofits working in the social sector, located in various countries. His current research interests include understanding the human factor in trucking distribution systems. 